\title{
Absorption of sugars by the piglet
}

\author{
By D. E. KIDDER, M. J. MANNERS; M. R. McCREA \\ AND A. D. OSBORNE \\ Departments of Veterinary Medicine and Animal Husbandry, University of Bristol
}

(Received 2 Fanuary 1968-Accepted 26 April 1968)

\begin{abstract}
I. Diets containing various sugar mixtures together with polyethylene glycol of high molecular weight as a marker were fed to pigs $I, 2$ and 3 weeks old. The piglets were slaughtered $2.5 \mathrm{~h}$ later, and the ratio of sugar to marker was determined in the contents of the alimentary tract as far as the caecum.

2. The greatest fall was found in the first part of the small intestine.

3. Glucose had always disappeared by the third quarter of the small intestine.

4. Xylose and fructose disappeared more slowly, especially in the younger pigs, but were usually absent from the contents of the last quarter of the small intestine.

5. Sucrose was removed far less completely, and the ratio of sucrose to marker frequently did not decrease along the second half of the small intestine. Sucrose was removed much less efficiently when it formed $15 \%$ of the diet than when it formed only $5 \%$, and much less efficiently by the younger than by the older pigs.
\end{abstract}

Judging by the effect on growth and health, some of the common sugars are much more satisfactory than others as nutrients for very young piglets, glucose and lactose being the best and sucrose the worst, while fructose is intermediate (Johnson, 1949; Becker, Ullrey \& Terrill, I954; Becker, Ullrey, Terrill \& Notzold, I954). This order of nutrient efficiency corresponds with the rise in blood sugar level after feeding these sugars (Dollar, Mitchell \& Porter, 1957; Kidder, Manners \& McCrea, 1963), and the concentrations of lactase and invertase in the intestinal mucosa of the piglet (Bailey, Kitts \& Wood, I956; Walker, 1959).

These methods of investigation give little information about the location of absorption or the extent to which the less readily absorbed sugars pass through the small intestine unabsorbed. To examine these points piglets were given diets containing different sugars mixed with polyethylene glycol of high molecular weight(PEG), a watersoluble marker which is not absorbed or altered in the gut. The piglets were slaughtered at different ages and the sugar to $\mathrm{PEG}$ ratio in various parts of the alimentary tract was compared with that in the diet. The results of some preliminary experiments on these lines have already been briefly reported (Kidder, Manners, McCrea, \& Osborne, I964).

\section{EXPERIMENTAL}

\section{Animals}

Thirty-three Large White $\times$ Wessex piglets from eight litters were used. Groups of three litter-mates matched for birth weight were taken, one piglet being killed at I week of age, another at 2 weeks and the third when 3 weeks old. They had been removed from the sow at 2 days of age and reared in individual cages with twice-daily feeding as described previously (Manners \& McCrea, I963). 


\section{Diets}

The composition of the stock glucose diet that each piglet received until three feeds before it was killed is given in Table $\mathrm{I}$. The feeds were prepared by mixing this diet ( $35 \mathrm{~g}$ diet per $\mathrm{kg}$ piglet per feed) with warm water at a rate of $\mathrm{I} \cdot 5 \mathrm{ml} / \mathrm{g}$ of diet. In addition, drinking water was given ad lib.

Table I. Composition of the stock glucose diet

$\begin{array}{lc} & \text { g per roo g } \\ \text { Glucose } & 45 \cdot 0^{*} \\ \text { Crude casein } & \mathbf{2 8 . 8} \\ \text { Dried whole milk } & \mathbf{2 0} \cdot 0 \\ \text { Mineral and vitamin } & 6 \cdot 2 \\ \text { supplements } \dagger & \end{array}$

* Replaced by test sugar mixtures in the experimental diets.

$\dagger$ These supplements contained, per roo g diet:

Minerals

$\begin{array}{lr}\text { Calcium } & \mathrm{I} \cdot 72 \mathrm{~g} \\ \text { Phosphorus } & 860 \mathrm{mg} \\ \text { Potassium } & 194 \mathrm{mg} \\ \text { Sodium } & 136 \mathrm{mg} \\ \text { Magnesium } & 41 \mathrm{mg} \\ \text { Iron } & 33 \mathrm{mg} \\ \text { Zinc } & 22 \mathrm{mg} \\ \text { Copper } & 3.6 \mathrm{mg} \\ \text { Manganese } & 400 \mu \mathrm{g} \\ \text { Iodine } & 330 \mu \mathrm{g}\end{array}$

Vitamins

\begin{tabular}{|c|c|}
\hline Choline chloride & I $45 \mathrm{mg}$ \\
\hline Nicotinic acid & $2 \cdot 73 \mathrm{mg}$ \\
\hline Calcium pantothenate & I.5 $1 \mathrm{mg}$ \\
\hline$\alpha$-tocopherol acetate & $5^{80 \mu \mathrm{g}}$ \\
\hline Thiamine hydrochloride & $248 \mu \mathrm{g}$ \\
\hline Riboflavine & I $7 \mathrm{I} \mu \mathrm{g}$ \\
\hline Pyridoxine hydrochloride & $134 \mu \mathrm{g}$ \\
\hline Folic acid & $83 \mu \mathrm{g}$ \\
\hline Menaphthone & $60 \mu \mathrm{g}$ \\
\hline Biotin & $12 \mu \mathrm{g}$ \\
\hline Cyanocobalamin & $6.9 \mu \mathrm{g}$ \\
\hline Vitamin A & 324 i.u. \\
\hline Cholecalciferol & 8 r i.u. \\
\hline
\end{tabular}

Table 2. Sugars in the experimental diets (as \% of diet excluding PEG)

\section{Diet}

Stock glucose diet

Galactose pre-feed diet

Expt $\mathrm{I}$ : diet

Expt 2: I Sucrose diet

2 Fructose diet

Expt 3: r High-sucrose diet

2 Low-sucrose diet
Sucrose

Glucose
Fructose

45
-
15
25
35
-

Xylose

Galactose

$\begin{array}{lll}- & - & - \\ - & - & 45 \\ 15 & 15 & - \\ - & - & - \\ \text { I0 } & - & - \\ - & 15 & 15 \\ - & 15 & 25\end{array}$

A basal diet was also prepared differing from that given in Table $\mathbf{I}$ only in the omission of the sugar. The test sugars dissolved in $0.5 \%$ PEG (PEG 4000 , Shell Chemical Co.) solution were added to this basal diet to give the experimental diets. These differed from the stock glucose diets only in that the $45 \%$ glucose had been replaced by different sugar mixtures as listed in Table 2, and the water had been replaced by $0.5 \%$ PEG solution. In Expts $x$ and 2, the experimental diets were given 
for the last three feeds before slaughter. In Expt 3, the experimental diets were given only for the last feed before slaughter, the previous two feeds being of the galactose pre-feed diet.

\section{Dissection}

Two and a half hours after the last feed the piglet was killed by injection of pentobarbitone sodium into the anterior vena cava. The body cavity was opened and the alimentary tract removed, clamped to prevent movement of contents, and divided into the stomach, the small intestine and the caecum. The small intestine was further divided by length into four quarters, labelled $\mathrm{A}$ (duodenal end), B, C and D. The contents of these sections were centrifuged for $10 \mathrm{~min}$ at $12000 \mathrm{~g}$ at $4^{\circ}$ and the supernatant liquid was analysed. These procedures were carried out as rapidly as possible, the interval between the death of the piglet and the centrifuging of the gut contents being ${ }^{5} 5^{-20} \mathrm{~min}$.

\section{Analytical procedures}

PEG was determined by taking $0.2 \mathrm{ml}$ of the material to be analysed and applying a modification of the turbidometric method described by Hydén (1955) for omasal and intestinal contents, faeces, etc. Our procedure differed from that of Hydén in two details. First, the gut contents were not diluted before taking samples, but merely centrifuged, and secondly, the interval between adding the trichloroacetic acid reagent and measuring the resultant turbidity was lengthened from 5 to $50 \mathrm{~min}$. We had found (Manners \& Kidder, 1968) that, in the presence of piglet gut contents, the turbidity produced by PEG was slightly greater than that produced by an aqueous solution containing the same amount of PEG. To correct for this, an appropriate amount of PEG-free piglet gut contents was included in the PEG standard, which was subjected to the whole analytical procedure.

For sugar determination the samples were deproteinized in Expt $\mathrm{I}$ by the method of Somogyi (1945) and in Expts 2 and 3 by the method of Somogyi (1930). Glucose was then determined by the method of Huggett \& Nixon (1957), fructose by the method of Roe (1934) and sucrose after hydrolysis by invertase, and determination of the increased glucose concentration. Xylose was determined by the method of Roe \& Rice (I948). From the value for fructose content (which included combined fructose) and that for sucrose content, the free fructose concentration could be calculated for the piglets on sucrose diets. The sugar and PEG concentrations were determined at the same time in the sugar-PEG mixture incorporated in the test feed.

In Expt 2 the sugars in the gut were also examined chromatographically by the methods previously given (Kidder et al. 1963) ).

\section{Calculations}

The extent of loss of the sugars from the lumen of the gut was assessed by calculating the 'residual sugar index' for each section of the gut. This was:

PEG concentration in solution added

$$
\begin{aligned}
& \frac{\text { sugar concentration in gut contents }}{\text { sugar concentration in solution }} \times \frac{\text { to food }}{\text { PEG concentration in gut contents }} \times \frac{100}{\mathrm{I}} \text {. } \\
& \text { added to food }
\end{aligned}
$$


This factor gives the sugar concentration in the gut contents as a percentage of the concentration which would have been present had no absorption or fermentation taken place.

To calculate the mean residual sugar index for a pair or group of piglets, an angle transformation was carried out on the percentage individual figures for the index. An arithmetic mean was then taken and the resulting mean angle transformed back to a percentage (Snedecor, I 953). This was to prevent a distorted mean which can otherwise occur when means of percentages are taken.

\section{RESULTS}

\section{Comparison of monosaccharides}

In Expt I, where the experimental diet was given for three successive feeds before slaughter, the concentrations of the sugars may be expected to show the actual concentrations of sugar along the gut of a piglet regularly given this type of diet. The

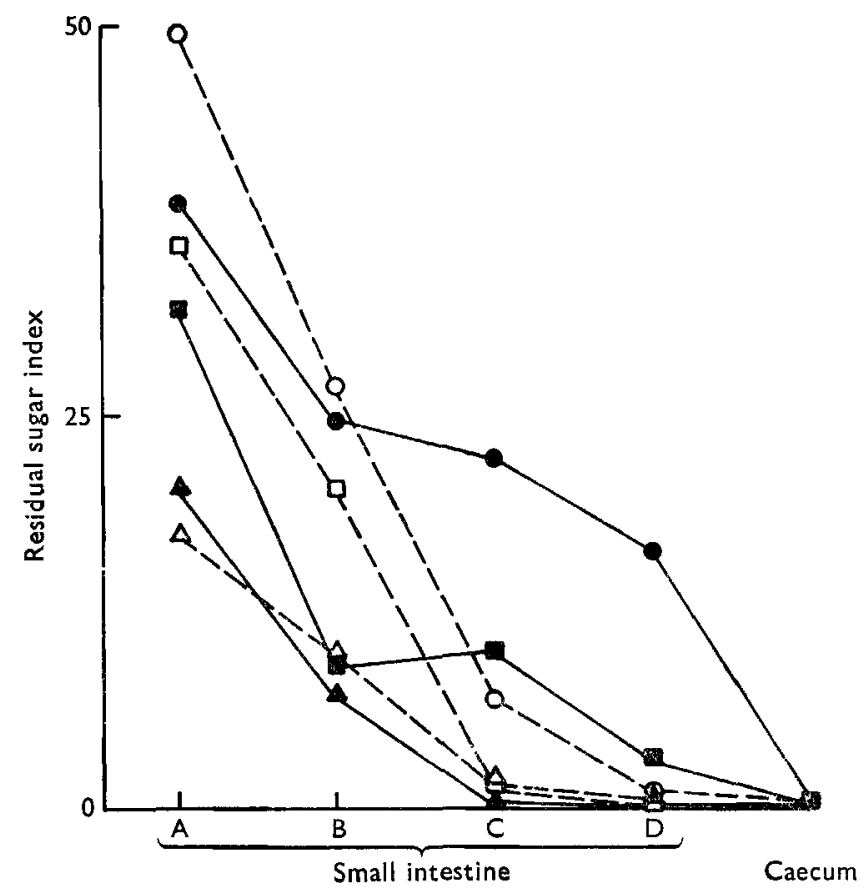

Fig. I. Expt 2. Residual sugar index (see p. 503) for fructose and sucrose in segments A-D (see p. 503) of the intestine and caecum of piglets. Each point is the mean of results for two pigs. $O$, I week old, fructose; $\square, 2$ weeks old, fructose; $\triangle, 3$ weeks old, fructose; $\bullet$, I week old, sucrose; $\square, 2$ weeks old, sucrose; $A, 3$ weeks old, sucrose.

PEG concentrations show the degree to which the food and digesta are diluted or concentrated by digestive secretions, by absorption, and by voluntary water intake. Table 3 shows the mean PEG and sugar concentrations in Expt $\mathrm{I}$. The residual sugar index of the gut contents is presented in Table 4, which shows the rapid removal of glucose in the first half of the small intestine, while fructose and xylose both 


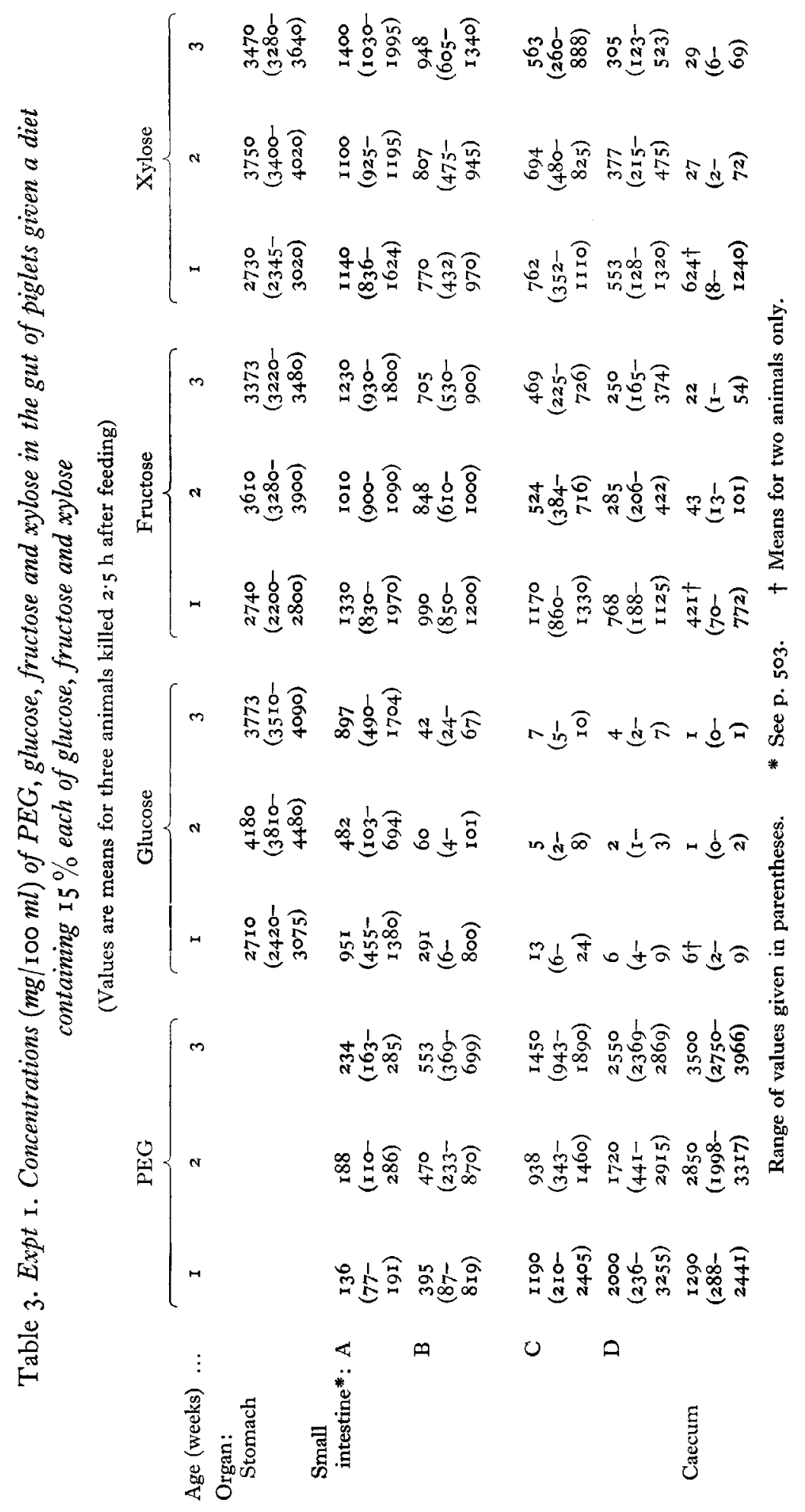




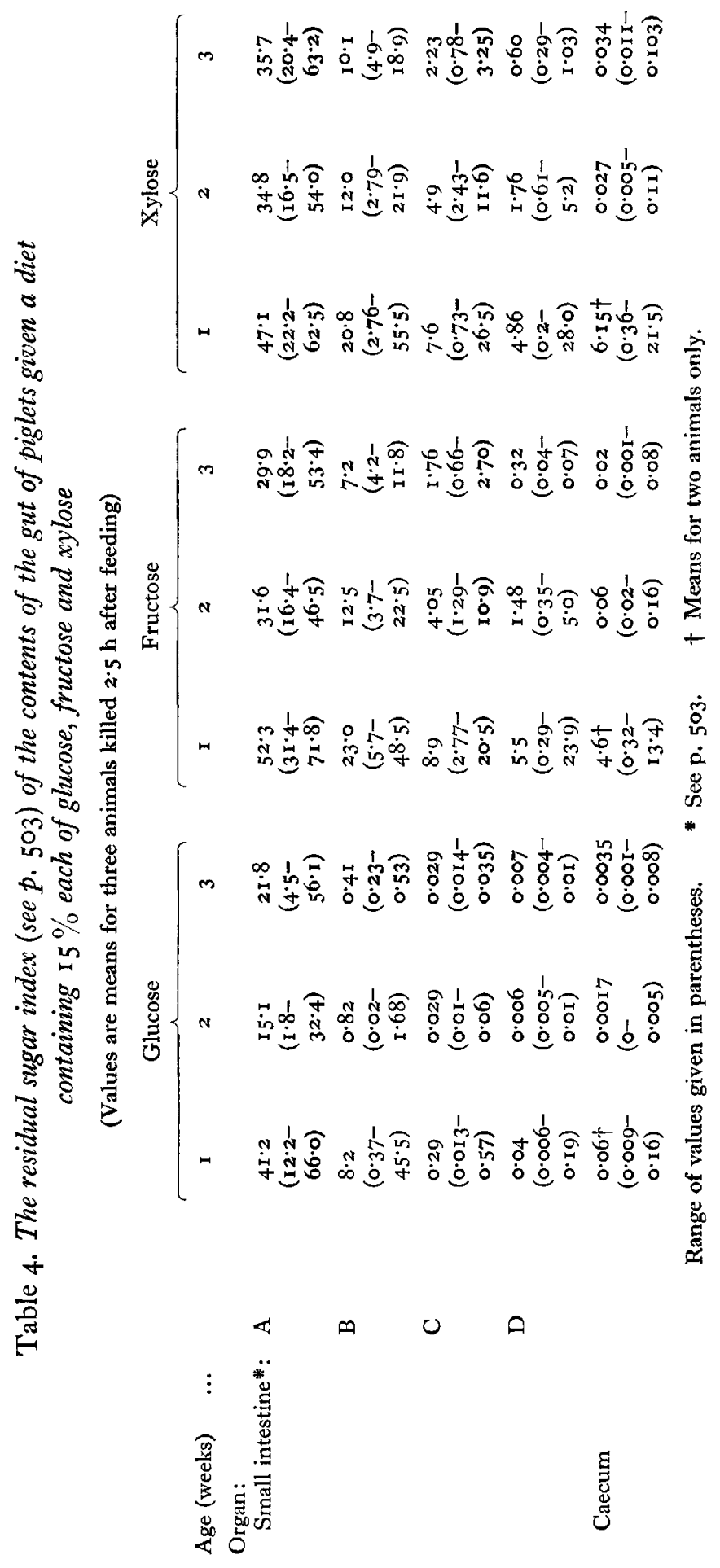


disappeared much more slowly. A close similarity in the fructose and xylose figures was found in almost every individual in which these sugars were compared.

\section{Comparison of sucrose and invert sugar}

Table 2 shows the composition of the diets. The sucrose-glucose and fructoseglucose diets were so devised that sucrose in the one was replaced by a $5 \% / 5 \circ$ glucosefructose mixture in the other. Comparison of the residual sugar index for sucrose, in the intestines of the piglets in Expt 2 receiving diet $\mathrm{I}$, with the index for fructose in the piglets on diet 2 is shown in Fig. I. The difference will be noted between the disappearance of fructose and of sucrose given at such a concentration as to cause the same initial level of fructose units. Fig. 2 gives the residual sugar index for glucose in the gut of these piglets.

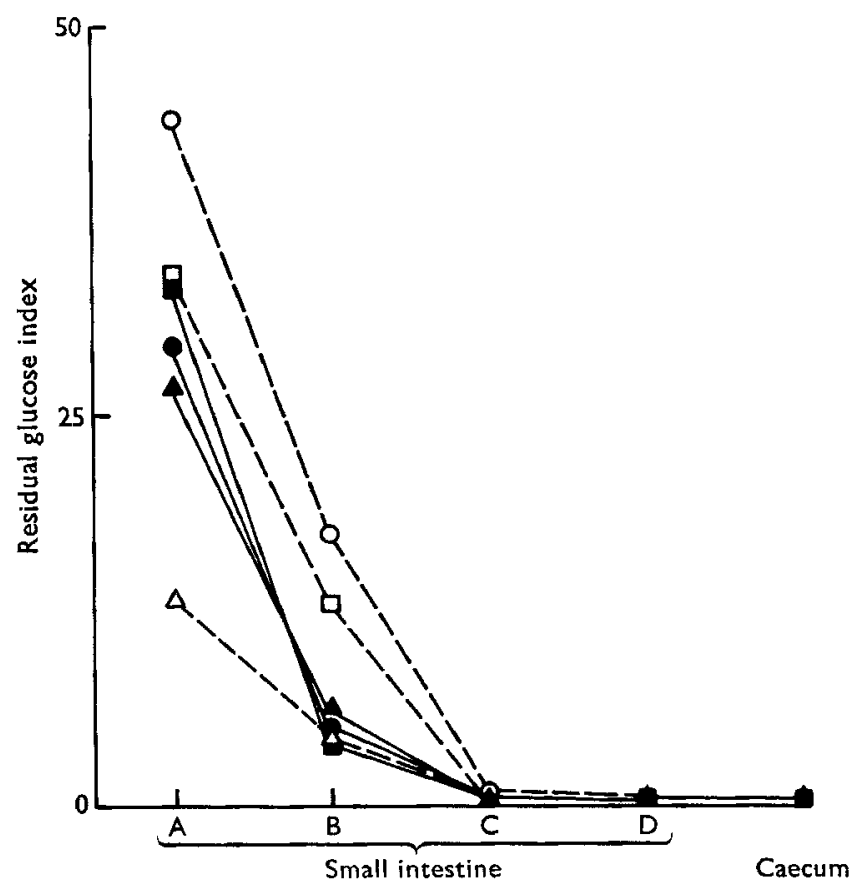

Fig. 2. Expt 2. Residual glucose index (see p. 503) in segments A-D (see p. 503) of the intestine and caecum of piglets. Diet I, sucrose-glucose (25\% glucose). Diet 2 , fructoseglucose ( $35 \%$ glucose). Each point is the mean of results for two pigs. $O$, I week old, diet I ; $\square, 2$ weeks old, diet $\mathbf{I} ; \triangle, 3$ weeks old, diet $\mathbf{1} ; 0$, I week old, diet $2 ; \mathbf{0}, 2$ weeks old, diet 2 ;

$\Lambda, 3$ weeks old, diet 2 .

On chromatographic examination, the sugars found in the gut contents were those included in the test mixture, some fructose in the piglets receiving sucrose, and lactose (from the dried milk) in the stomach and occasionally in traces in the first section of the small intestine. Our solvent system did not separate galactose from glucose sufficiently well to permit the detection of traces of galactose in the presence of large amounts of glucose. 


\section{Comparison of sucrose levels}

In Expt 3, two levels of sucrose were compared in litter-mates. A piglet was used at each age on each diet from each of two litters, and the results for each pair of piglets of the same age and diet from different litters were averaged. They are shown in Fig. 3. The residual sugar index, determined by the invertase method, which measures only unhydrolysed sucrose, shows that at each age sucrose is removed much more efficiently from the low ( $5 \%$ ) sucrose diet than from the high ( $15 \%)$. Total fructose was

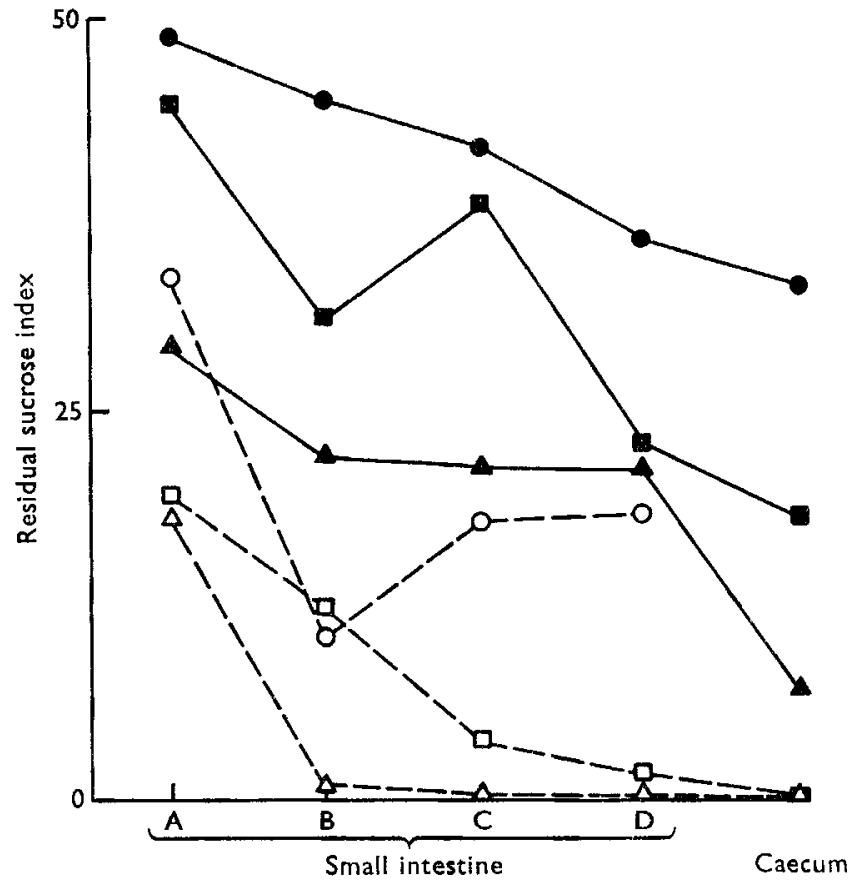

Fig. 3. Expt 3. Residual sucrose index (see p. 503) in segments A-D (see p. 503) of the intestine and caecum of piglets on different levels of sucrose. Each point is the mean of results for two piglets. $O$, I week old, low ( $5 \%$ ) sucrose diet; $\square, 2$ weeks old, low $(5 \%$ ) sucrose diet; $\triangle$, 3 weeks old, low $(5 \%)$ sucrose diet; $Q$, I week old, high ( $15 \%$ ) sucrose diet; $\mathbf{\square}, 2$ weeks old, high ( $15 \%$ ) sucrose diet; $\Delta, 3$ weeks old, high ( $5 \%$ ) sucrose diet.

also determined, and from this, the residual sugar index for fructose residues (combined as sucrose and free) was calculated. This gave curves essentially similar to those in Fig. 3 but slightly higher. The shape of the curves is typical of that found for sucrose in Expt 2 and different from that found with any other sugars. Very little glucose was found in any sample, indicating that little post-mortem hydrolysis of sucrose in the gut contents had occurred.

It was noticed on each occasion that the contents in the lower ileum and caecum were more fluid and in greater quantity in the piglets which had had the high-sucrose diet. This was particularly marked at I week old, where in neither of the piglets on the low-sucrose diet was it possible to get a large enough sample from the caecum for 
analysis, whereas in both the litter-mates on the high-sucrose diet ample material was present.

Xylose ( $15 \%$ ) was also included in both these experimental diets. Fig. 4 shows the residual sugar index for xylose for the two diets at the three ages.

\section{Molar concentration}

In Expts I and 2 (diet 2) where the concentrations of all the sugars present were measured, it was possible to make calculations of the total contribution of the sugars to the osmotic pressure of the gut contents. The ranges of molar concentrations are

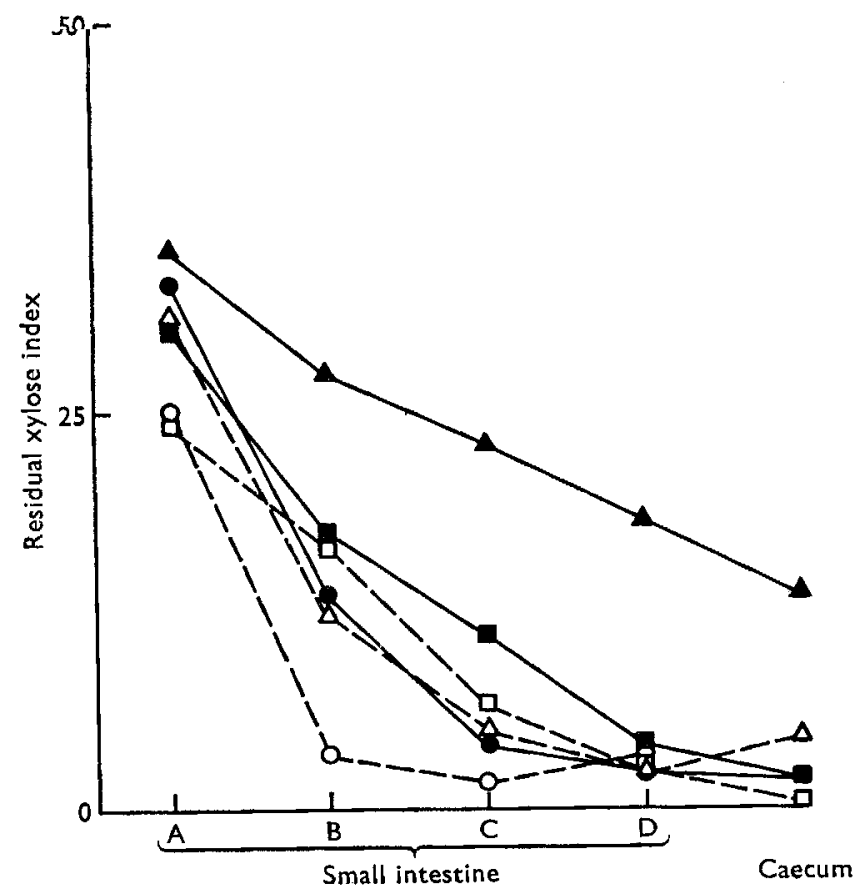

Fig. 4. Expt 3. Residual xylose index (see p. 503) in segments A-D (see p. 503) of the intestine and caecum of piglets on different levels of sucrose. Each point is the mean of results for two piglets. $O$, I week old, low $(5 \%$ ) sucrose diet; $\square, 2$ weeks old, low $(5 \%)$ sucrose diet; $\triangle$, 3 weeks old, low ( $5 \%$ ) sucrose diet; $O$, I week old, high ( $5 \%$ ) sucrose diet; $\mathbf{n}, 2$ weeks old, high $(15 \%)$ sucrose diet; $\Delta, 3$ weeks old, high (15\%) sucrose diet.

shown in Table 5. On the glucose-fructose-xylose diet, the molar concentration ranges in the small intestine (D) and the caecum were $19 \cdot 2-56 \cdot \mathrm{I}$ and $0 \cdot 8-10 \cdot 4 \mathrm{~m}$-moles $/ 1$. respectively in all but two piglets (both I week old) which had values of 70 and $15 \mathrm{I} \mathrm{m}$-moles/l. in small intestine $\mathrm{D}$, and 40 and 126 in the caecum.

In Expt 3, where two sucrose levels had been used, all the sugars except galactose were determined. Fig. 5 shows the total molar concentrations of the sugars other than galactose in sections $\mathrm{C}$ and $\mathrm{D}$ of the small intestine and in the caecum of the individual piglets in Expt 3. In each of the three individual segments, the total molar concentration of these sugars in every piglet on the high-sucrose diet was higher than in any piglet on the low sucrose diet. 


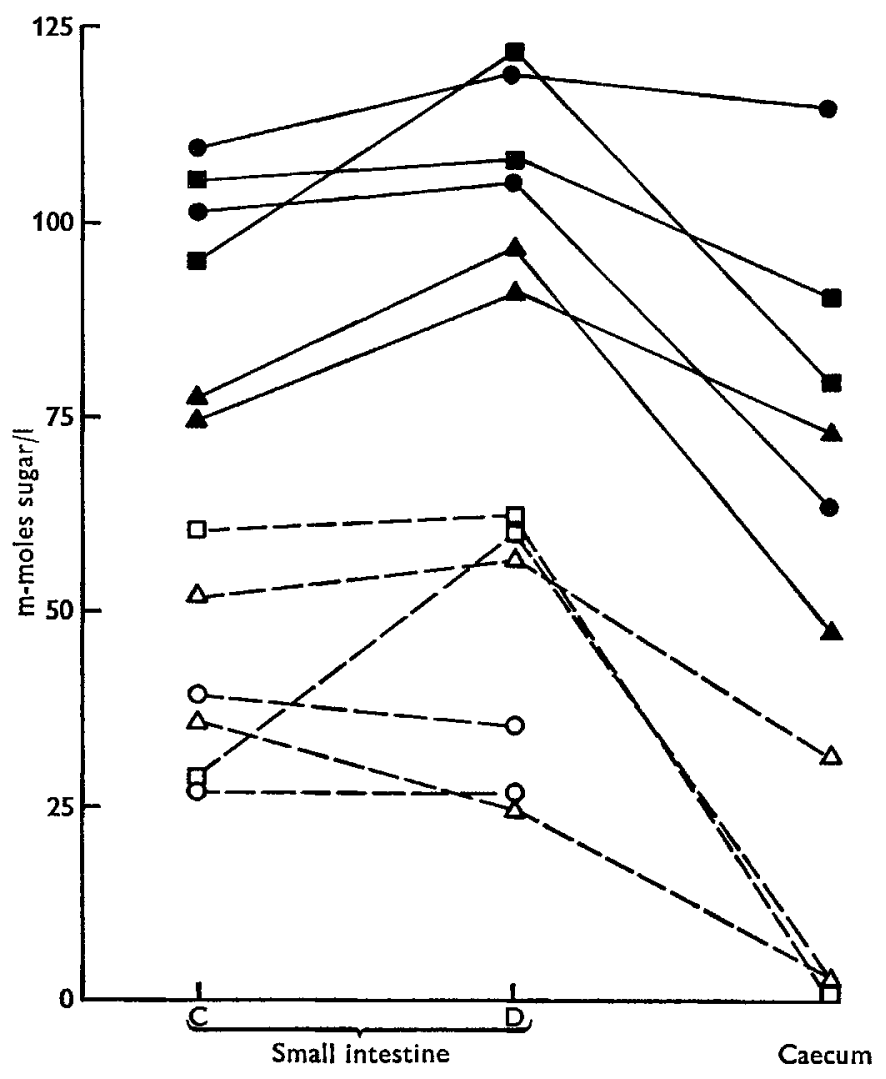

Fig. 5. Expt 3. Total molar concentrations of sugars other than galactose in segments C and D (sce p. 503) of the lower small intestine and caecum of individual piglets on high- and lowsucrose diets. Each point is the result for an individual piglet. $O$, I week old, low (5\%) sucrose diet; $\square, 2$ weeks old, low $(5 \%$ ) sucrose diet; $\triangle, 3$ weeks old, low ( $5 \%$ ) sucrose diet; -, I week old, high ( $5 \%$ ) sucrose diet; $\mathbf{\square}, 2$ weeks old, high (15\%) sucrose diet; $\Delta, 3$ weeks old, high (15\%) sucrose diet.

Table 5. Range of molar concentrations ( $m$-moles/l.) of sugar in the gut of piglets after three feeds of the experimental sugar-PEG diet

\begin{tabular}{|c|c|c|}
\hline & $\begin{array}{c}\text { Expt I } \\
\text { (glucose-fructose-xylose diet) } \\
\text { Range for } 9 \text { piglets }\end{array}$ & $\begin{array}{c}\text { Expt } 2 \text { diet } 2 \\
\text { (glucose-fructose diet) } \\
\text { Range for } 6 \text { piglets }\end{array}$ \\
\hline \multicolumn{3}{|l|}{ Organ: } \\
\hline Stomach & $413-734$ & $446-86 I$ \\
\hline $\begin{array}{r}\text { Small intestine*: } \\
\text { A } \\
\text { C } \\
\text { D }\end{array}$ & $\begin{array}{r}148-328 \\
66-156 \\
30-135 \\
\text { I9-15I }\end{array}$ & $\begin{array}{c}92-194 \\
48-132 \\
4-64 \\
3-23\end{array}$ \\
\hline Caecum & $0.8-126$ & $0.8-3.4$ \\
\hline
\end{tabular}

* See p. 503 . 
It is unlikely that galactose was present in substantial quantities in this part of the intestine, as intestinal absorption of galactose in all species examined is more rapid than that of any other natural sugars other than glucose, usually being similar to that of glucose (Cori, I925; Wilson, I962), and we have never found more than traces of glucose in this part of the intestine.

\section{DISCUSSION}

This type of experiment measures only the disappearance of the sugar from the lumen of the digestive tract. It does not distinguish between removal by absorption or by fermentation. Both probably occur in all sections of the tract, but to greatly differing extents. To avoid ill health due to diets of doubtful suitability, and, particularly, to avoid differences in health between groups being compared, the experimental sugars were given only for a few feeds, and in Expt 3, only for one feed. There was thus little time for any adaptive response by the gut mucosa of the type found in rats by Deren, Broitman \& Zamchek (1967), or for any change in the gut flora in response to the experimental diet. The comparisons between glucose and other sugars may have been affected by these circumstances.

In the course of this work we obtained evidence, presented in an accompanying publication (Manners \& Kidder, I968), that, in the stomach of piglets given this type of diet, PEG does not distribute in precisely the same water space as substances of lower molecular weight such as glucose. There appears to be some water space in the casein which is accessible to the glucose but not to the larger molecule of the marker. We have, therefore, not presented any finding on the stomach contents. As the more solid and the more fluid parts of the stomach contents may not have emptied together from the stomach, this distribution effect could have caused some degree of separation of marker and marked substance in the intestine. Because of this, we have restricted our conclusions to instances where large differences occurred between experimental treatments in calculated disappearance of sugars.

Most of the sugar disappeared in the first half of the small intestine, a large proportion of it in the first quarter. This is in agreement with the findings in man on glucose and lactose by Borgström, Dahlqvist, Lundh \& Sjovall (1957) and on sucrose by Gray \& Inglefinger ( 1965 ). A similar result was observed with glucose, fructose and sucrose in the rat by Dahlqvist \& Thompson ( 1963 ). The interval between feeding and slaughter $\left(2 \frac{1}{2} \mathrm{~h}\right)$ will have influenced the exact distribution of sugar in the small intestine, as reported in the rat by Dahlqvist $\&$ Thompson. This interval was chosen because we had found it to be the time of maximum blood glucose and fructose levels after administration of this type of feed (Kidder et al. 1963).

\section{Monosaccharides}

There was marked difference, in the extent of sugar disappearance from the lumen, between the sugars, and to a lesser degree between piglets of different ages. Glucose, as might be expected, disappeared most rapidly, and was never present in more than traces in the second half of the small intestine (Table 3, Fig. 2). This agrees with the 
findings in other species that glucose is absorbed from the intestine particularly efficiently, both in vivo (Hewitt, 1924; Cori, 1925) and in vitro (Darlington \& Quastel, 1953; Crane \& Mandelstam, 1960). Fructose and xylose disappeared much more slowly than glucose, particularly in the younger piglets, and showed a great similarity to one another in their rates of removal (Table 3). Fructose has been shown by Hewitt, Cori and many subsequent workers to be absorbed far more slowly than glucose but more rapidly than most other sugars. The mechanism of intestinal fructose absorption has not been studied in the pig, but in the guinea-pig (Darlington \& Quastel, I953; Ginsburg \& Hers, 1960), the hamster (Wilson \& Vincent, 1955), man (Öckerman \& Lundborg, 1965) and the rat (Kiyasu \& Chaikoff, 1957) it has been found to be very different from, and therefore probably not competitive with, the active absorption process for glucose.

Until recently it usually has been assumed that active absorption processes do not operate on pentoses such as xylose (Wilson \& Crane, 1958), but there is now considerable evidence that the glucose transport system has some action on xylose (Bogner, I96r; Saloman, Allums \& Smith, I96r; Alvarado, r964; Csáky \& Lassen, I964). This will mean that glucose, galactose and xylose will compete for the same transport system, so that absorption of xylose, which has the least affinity for this system, will be inhibited. This may have affected the absorption of xylose in the first half of the small intestine. Ill-effects which have been reported to result from feeding xylose to young piglets by Wise, Barrick, Wise \& Osborne (1954) were not likely to have developed in our experiments since the experimental diet contained rather less xylose than the lowest level fed by these authors and was given for only a few meals.

\section{Sucrose}

Comparison of sucrose removal in Expt 2 (diet I) with fructose removal (diet 2) shows clearly a difference, not only in rate at which the sugars were removed from the lumen, but in the shape of the curves obtained with the two sugars. The shape of the sucrose curve (Figs. I and 3 ) shows that sucrose was very poorly absorbed in the second half of the small intestine. It is well established that disaccharides are mainly split by enzymes located within or on the surface of the mucosa rather than by secretions into the lumen of the intestine (Rohmann \& Nagano, 1903; Dahlqvist \& Borgström, I96r; Miller \& Crane, 1961; Ruttloff, Friese \& Täufel, 1965), so the absorption of sucrose might be expected to correspond to the mucosal invertase concentrations. Dahlqvist (196r), in five mucosal samples from one adult pig, found lower invertase activity in the duodenum than in the rest of the small intestine, but Kojecký \& Matlocha (1964a,b), taking about twenty mucosal samples from each of two adult pigs, found all the invertase activity in the first half of the small intestine. Blair \& Tuba ( 1963$)$, in the rat, also found the invertase almost entirely in the first half of the small intestine; such a distribution would explain the shape of our sucrose absorption curves.

The invertase content of the small intestine mucosa of suckled piglets of different ages has been studied by Bailey et al. (1956) and by Walker (1959) who found an initially low invertase activity which increased rapidly over the first few weeks. These observations, taken together with our present results and our previous ones on the 
appearance of fructose in the plasma after administration of sucrose and invert sugar by mouth (Kidder et al. 1963), substantiate the hypothesis of Becker, Ullrey \& Terill (1954) that the unsatisfactory consequences of feeding sucrose to very young pigs were due to the inability of the piglet to split the sucrose linkage and the consequent retention of sucrose in the lumen of the gut. The latter authors considered that this would have an undesirable hydragogue effect. In agreement with this, Cunningham, Friend \& Nicholson $(1963)$, in a study of older $(50 \mathrm{~kg})$ pigs with re-entrant fistulas in the lower small intestine, found that where dietary sugars had not been absorbed in the part of the intestine before the fistula, there was considerable water retention in the lumen. This is further supported by our own findings on the osmolar concentrations of sugar in the lower ileum and caecum on the sucrose diets (Fig. 5). On the diet containing $15 \%$ sucrose the osmolarity in section $\mathrm{D}$ due to the sugars alone was more than one-third of the osmolarity of plasma. The retention of water in the lumen of the lower small intestine was also visibly much greater on the diet containing $15 \%$ sucrose than on that with $5 \%$. This experiment, comparing the two levels of sucrose, showed clearly how much more efficiently the intestine of the piglet can deal with a $5 \%$ level of sucrose. In other species diarrhoea and general ill-health result from feeding unsuitable sugars or sugars in excessive quantity. This has been shown in calves by Velu, Kendall \& Gardner ( 1963 ), and in lambs by Walker \& Faichney ( 1964$)$. Prader, Semenza \& Auricchio ( $196_{3}$ ) reviewed the conditions in man in which lack of one or more of the intestinal disaccharidases causes diarrhoea with very acid faeces and marked ill-health when the relevant disaccharide is fed. Weijers, van de Kamer, Mossel \& Dicke $(1960)$ showed that when such a diarrhoea was induced, the faeces contained greatly increased quantities of lactic, acetic and formic acids and showed some changes in bacterial flora. Such fermentation in the contents of the colon may contribute to the ill-effects of sucrose in the piglet.

We wish to acknowledge the help given by Dr M. R. Wilson in dissection of the piglets. Thanks are due to Mr A. Davis, Miss H. Wade, Miss P. Wakeman and Mr T. Williams for technical assistance, and to the Pig Industry Development Authority for a grant towards the cost of this work.

\section{REFERENCES}

Alvarado, F. (1964). Experientia 20, 302.

Bailey, C. B., Kitts, W. D. \& Wood, A. J. (1956). Can. F. agric. Sci. 35, 5 I.

Becker, D. E., Ullrey, D. E. \& Terrill, S. W. (1954). Archs Biochem. Biophys. 48, I 78.

Becker, D. E., Ullrey, D. E., Terrill, S. W. \& Notzold, R. A. (1954). Science, N.Y. 120, 345.

Blair, D. G. R. \& Tuba, J. (1963). Can. F. Biochem. Physiol. 41, 905.

Bogner, P. H. (1961). Proc, Soc. exp. Biol. Med. 107, 263.

Borgström, B., Dahlqvist, A., Lundh, G. \& Sjovall, J. (1957) F. clin. Invest. 36, I52 I.

Cori, C. F. (1925). F. biol.Chem. 66, 691.

Crane, R. K. \& Mandelstam, P. (1960). Biochim. biophys. Acta 45, 460.

Csáky, T. Z. \& Lassen, U. V. (1964). Biochim. biophys. Acta 82, 2 I 5.

Cunningham, H. M., Friend, D. W. \& Nicholson, J. W. G. (r963). Can. F. Anim. Sci. 43, 215.

Dahlqvist, A. (196r). Biochem. F. 78, 28 a.

Dahlqvist, A. \& Borström, B. (I96I). Biochem. $\mathcal{F}$. 8I, 4 I I.

Dahlqvist, A. \& Thompson, D. L. (1963). Y. Physiol., Lond. 167, 193. 
Darlington, W. A. \& Quastel, J. H. (1953). Archs Biochem. Biophys. 43, 194.

Deren, J. J., Broitman, S. A. \& Zamcheck, N. (1967). J. clin. Invest. 46, I86.

Dollar, A. M., Mitchell, K. G. \& Porter, J. W. G. (1957). Proc. Nutr. Soc. 16, xii.

Ginsburg, V. \& Hers, H. G. (1960). Biochim. biophys. Acta 38, 427.

Gray, G. M. \& Inglefinger, F. J. (1965). F. clin. Invest. 44, 427.

Hewitt, J. A. (1924). Biochem. Э. 18, 161.

Huggett, A. St G. \& Nixon, D. A. (1957). Lancet ii, 368.

Hydén, S. (1955). K. LantbrHögsk. Annlr 22, 139.

Johnson, S. R. (1949). Fedn Proc. Fedn Am. Socs exp. Biol. 8, 387.

Kidder, D. E., Manners, M. J. \& McCrea, M. R. (r963). Res. vet. Sci. 4, I3 r.

Kidder, D. E., Manners, M. J., McCrea, M. R. \& Osborne, A. D. (1964). Proc, int. Congr. Nutr. vi. Edinburgh, p. 497 .

Kiyasu, J. Y. \& Chaikoff, I. L. (1957). F. biol. Chem. 224, 935.

Kojecký, Z. \& Matlocha, Z. (1964a). Proc, int. Congr. Nutr. vi. Edinburgh, p. 629.

Kojecký, Z. \& Matlocha, Z. (I964b). Acta Universitatis Palackianae Olomucensis Fac, Med. 35, 59.

Manners, M. J. \& Kidder, D. E. (I968). Br. F. Nutr. 22, 5 I 5.

Manners, M. J. \& McCrea, M. R. (1963). Br. F. Nutr. 16, 475.

Miller, D. \& Crane, R. K. (r96r). Biochim. biophys. Acta 52, $28 \mathrm{r}$.

Ockerman, P. A. \& Lundborg, H. (1965). Biochim. biophys. Acta 105, 34.

Prader, A., Semenza, G. \& Auricchio, S. (1963). Schweiz, med. Wschr. 93, 97.

Roe, J. H. (1934). F. biol. Chem. ro7, I5.

Roe, J. H. \& Rice, E. W. (1948). F. biol. Chem. 173, 507.

Röhmann, F. \& Nagano, J. (1903). Pflügers Arch. ges. Physiol. 95, 533.

Ruttloff, H., Friese, R. \& Täufel, K. (1965). Hoppe-Seylers Z. physiol. Chem. 341, r34.

Saloman, L. L., Allums, J. A. \& Smith, D. E. (I96r). Biochem. biophys. Res. Commun. 4, 123.

Snedecor, G. W. (1953). Statistical Methods Applied to Experiments in Agriculture and Biology, p. 447. Iowa State College.

Somogyi, M. (1930). F. biol. Chem. 86, 655 .

Somogyi, M. (1945). F. biol. Chem. 160, 69.

Velu, J. G., Kendall, K. A. \& Gardner, K. E. (1963). F. Dairy Sci. 43, 546.

Walker, D. M. (1959). Y. agric. Sci., Camb. 52, 357 .

Walker, D. M. \& Faichney, G. J. (1964). Br. F. Nutr. r8, 209.

Weijers, H. A., van de Kamer, J. H., Mossel, D. A. \& Dicke, W. K. (1960). Lancet ii, 296.

Wilson, T. H. (1962). Intestinal Absorption, p. 78. Philadelphia: Saunders.

Wilson, T. H. \& Crane, R. K. (1958). Biochim. biophys. Acta 29, 30.

Wilson, T. H. \& Vincent, T. N. (I955). F. biol. Chem. 216, 85 I.

Wise, M. B., Barrick, E. R., Wise, G. H. \& Osborne, J. C. (1954). F. Anim. Sci. 13, $36_{5}$. 